\title{
Combinations of Personal Responsibility: Differences on Pre-service and Practicing Teachers' Efficacy, Engagement, Classroom Goal Structures and Wellbeing
}

\author{
Lia M. Daniels*, Amanda I. Radil and Lauren D. Goegan \\ Department of Educational Psychology, University of Alberta, Edmonton, AB, Canada
}

Pre-service and practicing teachers feel responsible for a range of educational activities. Four domains of personal responsibility emerging in the literature are: student achievement, student motivation, relationships with students, and responsibility for ones own teaching. To date, most research has used variable-centered approaches to examining responsibilities even though the domains appear related. In two separate samples we used cluster analysis to explore how pre-service $(n=130)$ and practicing $(n=105)$ teachers combined personal responsibilities and their impact on three professional cognitions and their wellbeing. Both groups had low and high responsibility clusters but the third cluster differed: Pre-service teachers combined responsibilities for relationships and their own teaching in a cluster we refer to as teacher-based responsibility; whereas, practicing teachers combined achievement and motivation in a cluster we refer to as student-outcome focused responsibility. These combinations affected outcomes for pre-service but not practicing teachers. Pre-service teachers in the low responsibility cluster reported less engagement, less mastery approaches to instruction, and more performance goal structures than the other two clusters.

Keywords: personal responsibility for teaching, teacher engagement, teaching efficacy, instructional practices, pre-service teachers, practicing teachers

\section{INTRODUCTION}

Pre-service and practicing teachers report feeling responsible for a host of activities including the developmental, social, and emotional needs of their students (Fischman et al., 2006; Lauermann, 2014). Although taking on these responsibilities is likely in the best interests of students, the impact of personal responsibility on teachers' cognitions and wellbeing is unknown. The common negative picture of pre-service teachers struggling to make the transition to practice (Alberta Teaches' Association, 2013) and practicing teachers as emotionally exhausted, overworked, stressed, and burned-out (Alberta Teachers' Association, 1999; Martin et al., 2012), suggests that perhaps feeling highly responsible for students may come with some costs. This picture is not unique to Canada, with similar descriptions being recorded for teachers in many countries including the United States (National Commission on Teaching and America's Future, 2007), England (Foster, 2017), and Australia (Australian Primary Principals' Association, 2006). The purpose of this research was to look how different combinations of personal responsibilities relate to pre-service and practicing teachers' sense of teacher efficacy, engagement, classroom goal structures, and wellbeing. 


\section{PERSONAL RESPONSIBILITY}

Lauermann and Karabenick's (2011b) conceptualize personal responsibility as "as a sense of internal obligation and commitment to produce or prevent designated outcomes, or that these outcomes should have been produced or prevented" (p. 135). The Teacher Responsibility Scale (TRS) captures the multifaceted nature of responsibility in four domains "that teachers would consider highly relevant for their professional lives" (p. 17): personal responsibility for student achievement, student motivation, relationships with students, and responsibility for their own teaching. On the one hand, these four domains of personal responsibility are closely related to some of the domains of teaching reported as most stressful for teachers including high-stakes student testing, disruptive students, poor relationships, and being evaluated (Manthei et al., 1996; Kyriacou, 2001; Montgomery and Rupp, 2005). On the other hand, teachers also report high levels of satisfaction and other pleasant outcomes as extending from their responsibilities (Bishay, 1996; Lauermann, 2014). We were interested in how responsibilities relate to three cognitions (sense of efficacy, engagement, and classroom goal structures) as well as an indicator of wellbeing in separate samples of pre-service and practicing teachers.

\section{Outcomes Associated with Personal Responsibility}

Sense of efficacy is defined as the extent to which a person feels capable to perform a task (Bandura, 2006). In the realm of teaching, sense of efficacy has been thoroughly researched with a high sense of efficacy often considered a marker of not only an effective teacher (Hattie, 2009; Klassen and Tze, 2014) but also a committed and less stressed teacher (e.g., Klassen and Chiu, 2011; Klassen and Durksen, 2014; Zee and Koomen, 2016). In creating the TRS, Lauermann and Karabenick (2013) demonstrated that although the four domains of personal responsibility were positively correlated with pre-service teachers' sense of efficacy in the same four domains, they could not be collapsed into a single structural model thus suggesting they represent different constructs. They also showed that teachers had different mean levels of endorsement depending on the domain: they felt more efficacious for meeting students' needs for motivation and achievement than they felt responsible for these domains; whereas, they felt more responsible than efficacious when it came to their own teaching.

It seems that personal responsibility may also impact teachers' engagement. Generally, teachers who feel personally responsible tend to be internally motivated, self-regulated, proactive, concerned about others, and sensitive to the consequences of their own actions (Guskey, 1981; Pelletier et al., 2002; Fischman et al., 2006; Ryan and Weinstein, 2009; Lauermann and Karabenick, 2011b; Lauermann, 2014). In interviews, teachers distinguish responsible teachers from irresponsible ones based on their quality of engagement.

Responsible teachers do their "job every day not just when being observed" (\#04HSq1). This included not only formal duties such as being on time, but also voluntary engagement: a responsible teacher "comes early, stays late and is never totally done with work" (\#13HSq2). Irresponsible teachers, on the other hand, were characterized by work avoidance: they do "as little work as possible" (\#03HSq4) and "they are late, demonstrate a lack of caring, make excuses and model inappropriate attitudes and actions. It is always someone else's job or not important to take initiative, follow through on communication such as talks with parents, notes home, lesson plans, etc.” (\#20ESq1B) (Lauermann, 2014, pp. 82-83).

These differences in quality of engagement may extend from the notion that personal responsibility is internalized and thus more adaptive than responsibility that is externally imposed. This distinction is important because teachers who experience high levels of being held responsible either in laboratory settings or through high stakes testing, administrative demands, and external mandates are more likely to rely on negative teaching strategies such as using more controlling language, providing less choice, and being more criticizing (Deci et al., 1982; Flink et al., 1990) than those who internalize responsibility in a personal way. Linking personal responsibility and classroom goal structures, Daniels et al. (2016) found that mastery-goal structures were negatively related to responsibility for achievement and positively related to responsibility for relationships; whereas, performancegoal structures were negatively related to responsibility for motivation. Lauermann (2013) found slightly different patterns whereby responsibility for motivation was positively related to performance goal practices, while responsibility for achievement and relationships predicted mastery goal practices. Berger et al. (2013) showed that of the four responsibilities for quality of teaching was positively related to autonomy supportive practices and structure and negatively related to classroom control and chaos.

Extending beyond their professional cognitions, teachers reported that although responsibility is a source of personal satisfaction and success for students it can also be a source of hard work and often requires personal compromise (Lauermann, 2014). Elsewhere, teachers have also described feelings of tension, stress, and even guilt arising from assuming too many responsibilities that they feel unable to meet (Broadfoot et al., 1988; Fischman et al., 2006). Although it seems that the positives associated with personal responsibility outnumber the negatives (Lauermann, 2014), there is also a possibility that a curvilinear relation exists between "felt responsibility and teachers' wellbeing such that too much responsibility and identification with too many poorly defined roles may lead to such negative consequences as burnout and decreased job satisfaction" (Lauermann and Karabenick, 2011b, p. 133).

A limitation of the research reviewed above is that it relied exclusively on variable-centered analyses and thus failed to account for different combinations of personal responsibility. There is theoretical and empirical evidence that the four domains of personal responsibility are not completely separate and thus these sorts of combinations are important to consider. 


\section{Theorized Relationships between Responsibilities}

Although any combination of personal responsibility is possible, two theoretical perspectives may provide insight into particular combinations for teachers that may be more nuanced than simply low or high levels of all responsibilities. First, according to Weiner (1985) cognitions related to responsibility extend from attributions for controllability. Of the four domains of personal responsibility, it could be argued that teachers have more control over their own teaching and establishing relationships with their students than over students' achievement and motivation. Thus, from an attributional perspective personal responsibilities for achievement and motivation may be more likely to be endorsed together because they represent outcomes that are more difficult for teachers to control. In turn, personal responsibilities for ones own teaching and relationships with students may be endorsed together because these are more proximal outcomes over which teachers can exert greater control.

The second framework that can be applied is Winter's (1992) work conceptualizing responsibility as a dispositional construct consisting of two components. The first component is the "must" component characterized by an internal sense of obligation, adherence to a moral or legal standard, and selfjudgment. The must component is proposed to focus on past outcomes and speculated to form first as a relatively immediate set of cognitions. The second component is referred to as the "social" or altruistic component characterized by concern for others and concern about the negative consequences of one's own actions. This social component is concerned with future outcomes and their consequences for the self and others. Winter suggests that the social component may develop over time with greater cognitive awareness of possible consequences. Teachers are legally responsibility for the quality of their own teaching and for student achievement. Arguably, these could be the very first cognitions that pre-service teachers adopt when they choose to enter the profession and thus they may map onto Winter's concept of "must" responsibility. In turn, personal responsibility for students' motivation and relationships with students feel conceptually more focused on the future and concerns for students making them likely to map onto Winter's "social" component.

The empirical data appears to favor the pairing based on Weiner (1985) more than Winter (1992). For example, when validating the scales Lauermann and Karabenick (2013) found that the correlation between responsibility for motivation and achievement amongst practicing teachers was $r=0.70$ with the next highest relationship between responsibilities for relationships and own teaching at $r=0.53(r=0.78$ and $r=0.70$, respectively, for pre-service teachers). A sample of pre-service teachers (Daniels et al., 2016) also demonstrated that the relationship between responsibility for motivation and achievement was the strongest $(r=0.60)$ aligning with Weiner (1985) but also showed a strong correlation between achievement and own teaching $(r=0.55)$ aligning with Winter (1992). Working with vocational teachers Berger et al. (2013) showed a narrower range of correlations $(r s=0.22-0.48)$ with the association between responsibility for achievement and motivation suggested by Attribution Theory $(r=0.47)$ essentially equivalent to that of achievement and relationships $(r=0.48)$, a pairing that wouldn't be predicted by either theoretical framework. These relationships suggest that there is value in taking a person-centered approach to examining personal responsibility. By doing so we can examine not just absolute quantity of responsibility but the combination of different responsibilities that maybe be particularly advantageous or not.

\section{Conceptual Framework for the Current Study}

To date there is no quantitative evidence on how teachers' combine personal responsibilities or on whether or not certain combinations of responsibility are more or less advantageous for pre-service and practicing teachers. We sought to bring empirical evidence to bear on whether or not personal responsibility is a double-edged sword by implementing a person-centered approach. The advantages of person-centered approaches have recently been highlighted (Wormington and LinnenbrinkGarcia, 2016) and many of those principles apply to the investigation of teachers' personal responsibility. For example, variable centered-approaches to personal responsibility may be disadvantaged by the high correlation between responsibility for motivation and achievement. Because person-centered approaches examine responsibility at the level of the individual this correlation is less problematic. Also, once profiles of individuals are identified, researchers can make comparisons on outcomes of interest. We have elected to look for differences on teacher efficacy, teacher engagement, classroom goal structures, and a measure of wellbeing. For pre-service teachers we operationalized wellbeing as satisfaction with life in general and for practicing teachers we operationalized wellbeing as burnout.

\section{MATERIALS AND METHODS}

Both pre-service and practicing teachers participated in this research, which used a correlational self-report research design approved by the University's Ethical Review Board. Consent was implied by completion of the survey. We had two research questions: (1) How do pre-service and practicing teachers' combine their personal responsibilities? (2) Do these combinations result in different levels of sense of teaching efficacy, engagement, classroom goal structures, and wellbeing?

\section{Participants and Procedures}

\section{Pre-service Teachers}

We recruited 139 pre-service teachers through a research participation pool. In exchange for $2.5 \%$ of their course grade participants completed a single online survey that contained questionnaires on personal responsibility as a teacher, sense of efficacy, engagement, classroom goal structures, and wellbeing. Participants ranged in age from 18 to $36(M=21.12$ years $)$ and were predominately females (82\%). Eight participants did not indicate any racial or ethnic background information and the remaining self-reported to be of White European descent (80\%) 
with a small group who identified themselves as Asian (10\%). More participants were training to be secondary school teachers (53.8\%) than elementary school teachers (41.5\%) and eight did not indicate their level. Students represented a range of majors the largest groups being generalists $(n=38)$ followed by Biology majors $(n=22)$, English $(n=12)$, Physical Education $(n=11)$, and Mathematics $(n=10)$. We identified eight univariate outliers and one participant had no data, thus all analyses are based on a final sample of 130 pre-service teachers.

\section{Practicing Teachers}

Data were collected from a convenience sample of practicing teachers $(n=147)$ recruited during 2 -days attendance at mandatory professional development conventions. At the request of research assistants who approached teachers with a clipboard, participants answered questionnaires related to their beliefs about personal responsibility as a teacher, sense of efficacy, engagement, and instructional practices. Participants were 22-72 years old ( $M=38$ years) and predominately females (82\%). The majority of participants self-reported to be Canadian of European descent (82\%), four participants indicated they were Aboriginal/First Nations, two Chinese, and 21 provided no information. Participants ranged in teaching experience from 0 to 40 years ( $M=10.4$ years). Of the total, 110 reported being full time teachers while the remaining indicated they were pre-service teachers attending the convention, part time, substitute teachers, or administrators. Six respondents were pre-school teachers, 74 taught elementary, 47 taught junior high school, 37 taught high school, suggesting that some teachers taught at more than one level. Participants also taught a wide range of subject areas including English Language Arts (21.8\%), science (18.4\%), math $(17.0 \%)$, social studies (17.0\%), and art (15\%). In finalizing the sample we excluded five univariate outliers, one person with no data, and restricted the sample to those who were employed in a full time teaching position resulting in a sample of 104 teachers.

\section{Measures}

\section{Demographic Measures}

Two demographic variables were included in our analyses for pre-service teachers: self-reported gender $(n=109$ female, 20 male, 1 missing) and level of teaching $(n=54$ elementary, 70 secondary, 6 missing). These two variables, plus years of teaching experience as a continuous variable were included for the practicing teachers: $n=90$ female, 14 male; $n=49$ elementary, 52 junior/senior high school, 3 missing; $M=10.12$ years; $S D=8.42$.

\section{Responsibility}

We used the TRS (Lauermann and Karabenick, 2013) to assess personal responsibility. For pre-service teachers the statement "Imagine that you have classes of your own" was added to the standard instructions "To what extent would you feel PERSONALLY responsible that you should have prevented each of the following?" Fourteen items measured the following four areas of personal responsibility: student motivation, student achievement, relationships with students, and their own teaching. Sample items and descriptive statistics for all variables are presented in Table 1.

\section{Teacher Sense of Efficacy}

We used 11 of the 12 items from the short form of the Teacher Sense of Efficacy Scale (TSES), developed by Tschannen-Moran and Woolfolk Hoy (2001). We excluded the item "to what extent can you provide an alternative explanation or example when students are confused?" on the basis that it could not be easily adapted for pre-service teachers. In practicing teachers we excluded "How confident are you that you will be able to assist families in helping their children do well in school" because it has shown poor factor loading in other samples of Canadian teachers (Klassen et al., 2009). Although the TSES can be divided into efficacy for instructional strategies, classroom management, and student engagement, generally pre-service teachers lack sufficient experience to distinguish the factors and thus it is recommended to use a total sense of teaching selfefficacy score (Tschannen-Moran and Woolfolk Hoy, 2001). We created a single indicator of sense of teaching efficacy in both samples.

\section{Engagement}

We used the Engaged Teacher Scale (ETS; Klassen et al., 2013) to measure the degree of attention and absorption teachers feel (or pre-service teachers anticipate feeling) during teachingrelated activities. In response to the directions "Below you will find a list of statements describing your experiences as a [future] teacher. Please indicate your personal response to each of these statements by selecting the number that best represents your answer," participants rated items on cognitive engagement, emotional engagement, social engagement with students, and social engagement with colleagues. The ETS has been used as a single composite score for teacher engagement (Klassen et al., 2013; Durksen, 2015) as we have done here.

\section{Instructional Practices}

We used The Patterns of Adaptive Learning Scale (PALS; Midgley et al., 2000) to assess mastery and performance classroom goal structures. The items and instructions were adjusted slightly in order to accommodate pre-service teachers' intentions: “The following items are about what type of classroom you intend to establish once teaching. Please think about things you plan to do when you have your own classroom". Practicing teachers received the original instructions.

\section{Indicators of Wellbeing}

We operationalized wellbeing differently for pre-service and practicing teachers. Pre-service teachers responded to the five items on the Satisfaction with Life Scale (Diener et al., 1985). The scale is intended to measure general cognitive appraisals of one's current satisfaction with life. Diener et al. (1985) offered cut-off scores to use as benchmarks of satisfaction: 31-35 extremely satisfied, 26-30 satisfied, 21-25 slightly satisfied, 20 neutral, 15-19 slightly dissatisfied, 10-14 dissatisfied, 5-9 extremely dissatisfied. The mean score reported by pre-service teachers in this sample was $26.49(S D=6.09)$ suggesting these participants were on average "satisfied." For practicing teachers we operationalized wellbeing in terms of burnout and thus they rated nine items from an abbreviated version of the 
TABLE 1 | Descriptive statistics for all study variables.

\begin{tabular}{|c|c|c|c|c|c|c|c|c|c|}
\hline \multirow[t]{2}{*}{ Variable (number of items) } & \multirow[t]{2}{*}{ Sample item and response scale } & \multicolumn{4}{|c|}{ Pre-service teachers $n=130$} & \multicolumn{4}{|c|}{ Practicing teachers $n=105$} \\
\hline & & Range & $M$ & $S D$ & Alpha & Range & $M$ & $S D$ & Alpha \\
\hline $\begin{array}{l}\text { Responsibility for } \\
\text { achievement (4) }\end{array}$ & $\begin{array}{l}\text { I would feel personally responsible if a student of mine } \\
\text { had very low achievement }(1=\text { not at all; } \\
7=\text { completely })\end{array}$ & $12-28$ & 20.07 & 3.32 & 0.71 & $4-28$ & 18.73 & 5.41 & 0.71 \\
\hline $\begin{array}{l}\text { Responsibility for } \\
\text { motivation (4) }\end{array}$ & $\begin{array}{l}\text { I would feel personally responsible if a student of mine } \\
\text { was not interested in the subject I teach }(1=\text { not at all; } \\
7=\text { completely) }\end{array}$ & $5-26$ & 15.74 & 4.53 & 0.83 & $5-28$ & 17.24 & 6.06 & 0.93 \\
\hline $\begin{array}{l}\text { Responsibility for } \\
\text { relationships ( } 3 \text { ) }\end{array}$ & $\begin{array}{l}\text { I would feel personally responsible if a student of mine } \\
\text { thought he/she could not count on me when he/she } \\
\text { needed help ( } 1=\text { not at all; } 7=\text { completely) }\end{array}$ & $12-21$ & 18.40 & 2.29 & 0.78 & $3-21$ & 16.12 & 3.99 & 0.78 \\
\hline $\begin{array}{l}\text { Responsibility for own } \\
\text { teaching (3) }\end{array}$ & $\begin{array}{l}\text { I would feel personally responsible if a lesson I taught } \\
\text { was not as effective for student learning as I could have } \\
\text { possibly made it ( } 1=\text { not at all; } 7=\text { completely) }\end{array}$ & $14-21$ & 19.02 & 1.73 & 0.62 & $9-21$ & 17.14 & 2.96 & 0.86 \\
\hline $\begin{array}{l}\text { Sense of teaching efficacy } \\
\text { (11) }\end{array}$ & $\begin{array}{l}\text { How confident are you that you [will be] are able to } \\
\text { control disruptive behavior in the classroom? } \\
(1=\text { nothing; } 9=\text { a great deal })\end{array}$ & 43-96 & 71.35 & 9.84 & 0.86 & 49-99 & 80.42 & 9.74 & 0.90 \\
\hline Teacher engagement (16) & $\begin{array}{l}\text { While teaching, I [will] work with intensity. ( } 1 \text { = never, } \\
4=\text { sometimes, } 7 \text { = always) }\end{array}$ & $77-112$ & 101.92 & 7.59 & 0.91 & $64-112$ & 98.96 & 9.41 & 0.91 \\
\hline $\begin{array}{l}\text { Classroom mastery } \\
\text { structures (4) }\end{array}$ & $\begin{array}{l}\text { Providing several different activities during class so that } \\
\text { students can choose among them ( } 1=\text { strongly } \\
\text { disagree; } 5=\text { strongly agree) }\end{array}$ & $10-20$ & 17.02 & 2.00 & 0.51 & $8-20$ & 15.17 & 2.77 & 0.72 \\
\hline $\begin{array}{l}\text { Classroom performance } \\
\text { structures (5) }\end{array}$ & $\begin{array}{l}\text { Giving special privileges to students who do the best } \\
\text { work ( } 1=\text { strongly disagree; } 5=\text { strongly agree) }\end{array}$ & $5-23$ & 11.01 & 3.35 & 0.69 & $5-21$ & 11.14 & 4.09 & 0.79 \\
\hline $\begin{array}{l}\text { Measure of wellbeing }{ }^{a} \\
\text { (5 and } 9)\end{array}$ & $\begin{array}{l}\text { Life satisfaction pre-service: In most ways, my life is } \\
\text { close to my ideal ( } 1=\text { strongly disagree; } 7=\text { strongly } \\
\text { agree) Burnout practicing: I feel frustrated by my job. } \\
\text { ( } 1=\text { never; } 7 \text { = always) }\end{array}$ & $6-35$ & 26.49 & 6.09 & 0.90 & $9-39$ & 21.52 & 6.95 & 0.75 \\
\hline
\end{tabular}

aWellbeing was operationalized as life satisfaction in pre-service teachers and burnout in practicing teachers.

Maslach Burnout Inventory (McManus et al., 2002) tapping into emotional exhaustion, depersonalization, and personal accomplishment $(1=$ strongly disagree to $7=$ strongly agree $)$ rating scale. We created a composite score summing all nine items. Although this abbreviated version does not offer specific cut-off scores, the MBI Manual divides normative samples into thirds with each third corresponding to low, average, or high burnout (Maslach et al., 1996). Extrapolating from this practice, scores 9-27 would indicate low burnout, 28-54 would indicate average burnout, and 55-63 would suggest high levels of burnout.

\section{Rationale for Analyses and Hypotheses}

All analyses were conducted separately for pre-service and practicing teachers. As preliminary analyses we correlated all variables to examine zero-order associations. Next we standardized the responsibility scales before conducting a $k$-means cluster analysis. We chose to use a $k$-means cluster analysis because we were interested in minimizing the variance within a cluster and maximizing variance between clusters (Huberty et al., 2005). K-means is a variance partitioning non-hierarchical clustering technique in which the number of cluster solutions is left to the discretion of the researcher and should be guided by theory and meaningful interpretation of the cluster solutions. We examined the resultant clusters from the theoretical perspectives of Weiner (1985) and Winter
(1992) and expected either a three or four cluster solution to best describe the data with low and high responsibility clusters paired with one or two other theoretically grounded groupings. We examined each cluster in terms of adequately representing elementary and secondary level participants and females and males with chi-square tests. Finally, we used analysis of covariance to examine differences between the clusters on sense of efficacy, engagement, classroom goal structures, and wellbeing while covarying gender, teaching level, and, in the practicing teacher sample, years of teaching experience. We hypothesized the high responsibility cluster would have higher levels of sense of efficacy, engagement, mastery goal structures, and wellbeing but lower levels of performance instructional practices than the low responsibility cluster. We did not have a priori hypotheses for the other combinations of responsibilities. All significant main effects of cluster membership were followed up by testing all possible pairwise comparisons using $t$-tests and a conservative Bonferroni adjusted significance level $(\alpha=0.05 / 5=0.01)$.

\section{RESULTS}

\section{Zero-Order Correlations}

All correlations are presented in Table 2. The demographic variables were largely unrelated to the responsibility variables 
TABLE 2 | Correlations for all study variables.

\begin{tabular}{|c|c|c|c|c|c|c|c|c|c|c|c|c|}
\hline Variable & 1 & 2 & 3 & 4 & 5 & 6 & 7 & 8 & 9 & 10 & 11 & 12 \\
\hline (1) Years teaching experience & - & 0.03 & 0.07 & -0.08 & -0.14 & -0.13 & 0.04 & $0.38^{* *}$ & $0.26^{* *}$ & $0.33^{* *}$ & -0.18 & $-0.39 * *$ \\
\hline (2) Gender ${ }^{a}$ & - & - & $0.25^{* *}$ & 0.15 & 0.11 & $0.26^{* *}$ & 0.10 & -0.10 & 0.06 & 0.13 & -0.11 & 0.09 \\
\hline (3) Teaching level ${ }^{b}$ & - & 0.15 & - & 0.13 & 0.14 & $0.22^{* *}$ & 0.11 & -0.16 & 0.08 & 0.10 & -0.14 & -0.03 \\
\hline (4) Responsibility for motivation & - & 0.01 & -0.02 & - & $0.78^{* *}$ & $0.47^{* *}$ & $0.59^{* *}$ & -0.16 & 0.01 & 0.15 & 0.10 & 0.05 \\
\hline (5) Responsibility for achievement & - & -0.11 & 0.04 & $0.47^{* *}$ & - & $0.54^{* *}$ & $0.71^{* *}$ & -0.13 & 0.02 & $0.24^{* *}$ & 0.02 & 0.06 \\
\hline (6) Responsibility for relationships & - & -0.01 & -0.07 & 0.12 & $0.23^{* *}$ & - & $0.65^{* *}$ & -0.05 & 0.13 & $0.27^{* *}$ & -0.15 & -0.14 \\
\hline (7) Responsibility for own teaching & - & -0.04 & -0.05 & 0.08 & 0.13 & $0.30^{* *}$ & - & -0.03 & 0.13 & $0.24^{* *}$ & -0.05 & -0.07 \\
\hline (8) Teacher efficacy & - & 0.13 & -0.12 & -0.14 & -0.14 & 0.01 & -0.11 & - & $0.57^{* *}$ & $0.29^{* *}$ & 0.10 & $-0.47^{* *}$ \\
\hline (9) Teacher engagement & - & -0.17 & -0.08 & 0.05 & 0.17 & $0.32^{* *}$ & $0.30 * *$ & 0.14 & - & $0.25^{* *}$ & 0.03 & $-0.48 * *$ \\
\hline (10) Mastery approaches & - & $0.21^{*}$ & -0.17 & -0.12 & -0.02 & 0.09 & $0.32^{* *}$ & -0.07 & $0.28^{* *}$ & - & 0.01 & $-0.25^{*}$ \\
\hline (11) Performance approaches & - & 0.08 & 0.08 & 0.07 & -0.05 & -0.05 & $-0.35^{* *}$ & 0.05 & -0.11 & -0.16 & - & 0.13 \\
\hline (12) Measure of wellbeing ${ }^{C}$ & - & $0.26^{* *}$ & -0.04 & -0.07 & -0.01 & 0.04 & 0.01 & $0.22^{*}$ & $0.26^{* *}$ & 0.04 & -0.02 & - \\
\hline
\end{tabular}

Coefficients on the bottom half of the matrix are pre-service teachers and coefficients on the top half of the matrix are practicing teachers. ${ }^{*} p<0.05 ;{ }^{* *} p<0.01$.

$\mathrm{a}\left(1=\right.$ male; 2 = female); ${ }^{\mathrm{b}}$ teaching level $\left(1\right.$ = elementary; 2 secondary); ${ }^{\mathrm{c}}$ For pre-service wellbeing was measured by the Satisfaction with Life Scale (Diener et al., 1985$)$.

For practicing teachers wellbeing was measured by burnout (McManus et al., 2002).

or the outcomes for pre-service teachers. The one exception was that female pre-service teachers were more inclined toward mastery approaches to instruction than males. For practicing teachers, gender and teaching level both correlated positively and significantly with responsibility for relationships such that women and secondary teachers felt more responsible in this domain. The longer participants had been teaching the more efficacious, engaged, and committed to mastery practices they reported feeling.

\section{Cluster Analysis}

$K$-means cluster analyses were run separately specifying two-, three-, and four-cluster solutions. Based on the combinations supported by Attribution Theory (Weiner, 1985), we selected the three-cluster solution as the most meaningful for both pre-service and practicing teachers. Final cluster centroids representing the physical "center" of the cluster as defined by the average of all the scores constituting the cluster are presented in Table 3. For both samples, we labeled the first cluster low responsibility because it was characterized by centroids $<0$ for each domain of responsibility. The second cluster for both samples had the highest centroids and thus we labeled it high responsibility. The third clusters differed between pre-service and practicing teachers. For preservice teachers we labeled the third cluster teacher-focused responsibility because it combined high levels of responsibility for relationships and own teaching with low responsibility for motivation and achievement. For practicing teachers, the third cluster had high levels of responsibility for motivation and achievement and a low level of responsibility for relationships and thus we labeled this cluster student-outcome focused responsibility.

Neither the clusters of pre-service nor practicing teachers differed significantly from each other in terms of the distribution of teaching level or gender [pre-service teaching level, $\chi^{2}(2)=1.89$, gender, $\chi^{2}(2)=0.41$; practicing teaching level, $\chi^{2}(2)=1.38, p>0.05$, gender $\chi^{2}(2)=1.59$, all ps $>0.05]$. Because of our interest to also covary years of teaching experience in practicing teachers, we examined the distribution of experience across the three clusters. The low responsibility cluster was characterized by the most teaching experience, $M=12.29$ years, $S D=9.15$ years. The high responsibility cluster had $M=9.31$ years, $S D=8.00$ years and the student-outcome focused responsibility cluster had the fewest years, $M=8.35$ years, $S D=7.78$ years. These differences were not statistically significant: $F(2,98)=1.93$, $p>0.05$.

In each sample, we used four one-way ANOVAs to test for significant omnibus differences between the clusters (Table 3). For pre-service teachers all $F$-statistics were significant as were all but three follow-up pair-wise comparisons. The low responsibility and teacher-focused responsibility clusters did not differ on responsibility for achievement, $t(124)=0.76$, $p>0.05$, meaning these two clusters endorsed similar levels of this responsibility. The high responsibility cluster and the teacher-focused responsibility cluster did not differ on relationships $t(124)=0.41, p>0.05$ or own teaching $t(124)=-0.29, p>0.05$, meaning that these two clusters represent similar levels of responsibility for relationships and own teaching but paired with either high or low levels of the other two domains of responsibility. For practicing teachers, all clusters differed from each other significantly except for the low responsibility cluster and the student-outcome focused responsibility cluster on responsibility for relationships. In other words, these two clusters reported similar levels of responsibility for relationships, $t(101)=0.52, p>0.05$. The means and standard deviations are presented as context for the pairwise comparisons (Table 3); however, they are not the primary source of interpretation for the clusters. Raw means can only be compared horizontally across clusters and not vertically within the cluster. Comparison of means across clusters, and cluster centroids within clusters, most accurately reflect the overall composition of the clusters and were used in determining the most suitable label for each cluster (Huberty et al., 2005). 


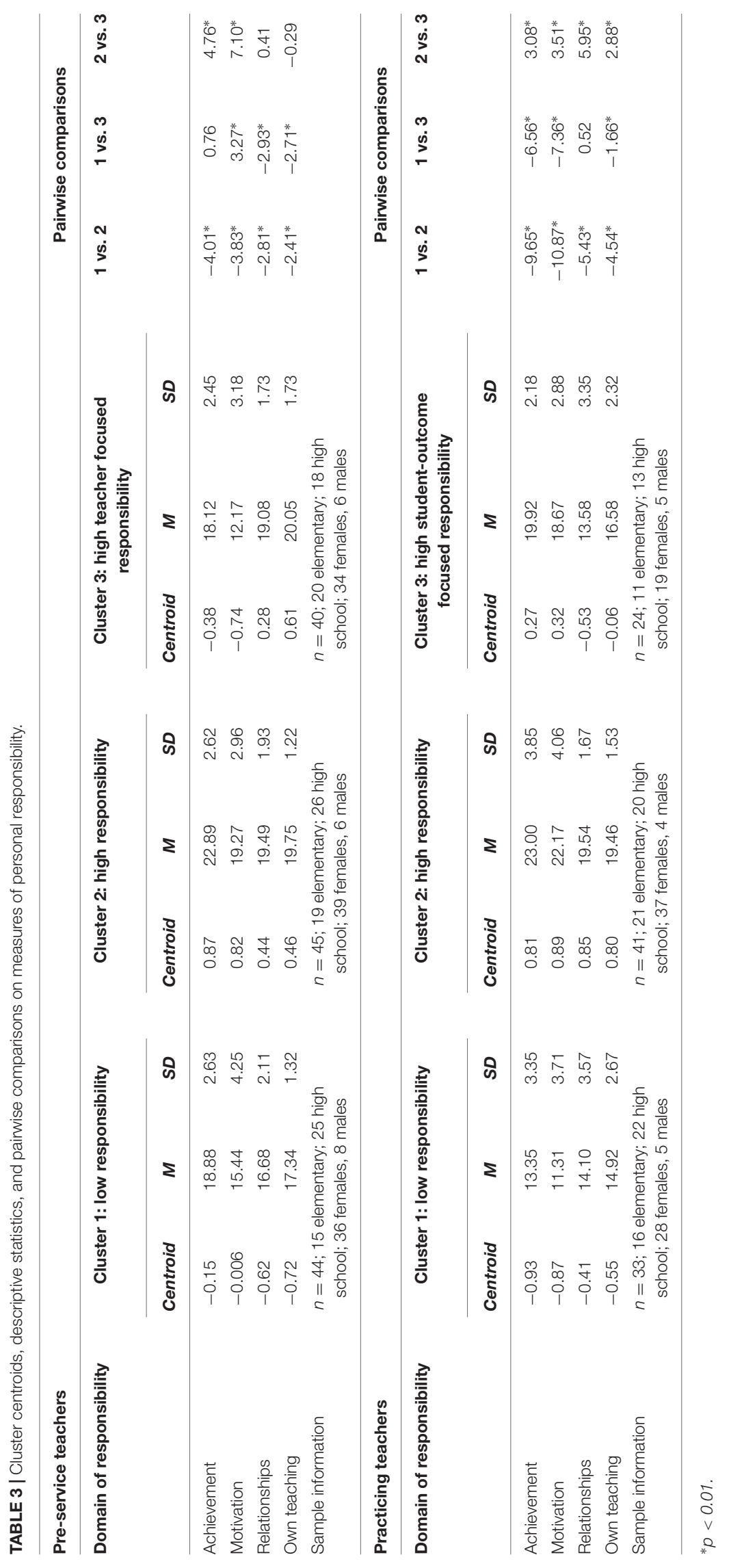


TABLE 4 | Analysis of covariance.

\begin{tabular}{|c|c|c|c|c|c|c|c|c|c|c|c|c|}
\hline \multirow{2}{*}{$\begin{array}{l}\text { Dependent variable } \\
\text { Pre-service teachers }\end{array}$} & \multicolumn{3}{|c|}{ Cluster } & \multicolumn{3}{|c|}{ Gender } & \multicolumn{3}{|c|}{ Teaching level } & \multicolumn{3}{|c|}{ Years experience } \\
\hline & Ms & $\boldsymbol{F}$ & $\eta^{2}$ & Ms & $\boldsymbol{F}$ & $\eta^{2}$ & Ms & $\boldsymbol{F}$ & $\eta^{2}$ & & & \\
\hline Teacher efficacy & 18.07 & 0.19 & 0.003 & 201.31 & 2.08 & 0.018 & 198.17 & 2.05 & 0.018 & - & - & - \\
\hline Teacher engagement & 391.03 & $7.43^{* *}$ & 0.11 & 118.05 & 2.24 & 0.019 & 12.73 & 0.24 & 0.002 & - & - & - \\
\hline Mastery & 16.05 & $4.35^{* *}$ & 0.07 & 13.02 & 3.53 & 0.029 & 6.28 & 1.70 & 0.014 & - & - & - \\
\hline Performance & 64.33 & $6.28^{* *}$ & 0.10 & 5.07 & 0.49 & 0.004 & 2.53 & 0.25 & 0.002 & - & - & - \\
\hline Satisfaction with life & 30.97 & 0.86 & 0.01 & 325.24 & $9.01^{* *}$ & 0.07 & 0.21 & 0.006 & 0.000 & & & \\
\hline \multicolumn{13}{|l|}{ Practicing teachers } \\
\hline Teacher efficacy & 80.07 & 1.12 & 0.03 & 45.48 & 0.64 & 0.01 & 301.38 & $4.23^{*}$ & 0.05 & 1207.85 & $16.95^{* * *}$ & 0.16 \\
\hline Teacher engagement & 94.17 & 1.38 & 0.03 & 146.36 & 2.14 & 0.02 & 55.94 & 0.82 & 0.01 & 792.34 & $11.58^{* *}$ & 0.12 \\
\hline Mastery & 3.62 & 0.51 & 0.01 & 2.91 & 0.41 & 0.01 & 28.90 & $4.07^{*}$ & 0.04 & 95.23 & $13.41^{* * *}$ & 0.13 \\
\hline Performance & 15.11 & 1.05 & 0.02 & 2.54 & 0.18 & 0.002 & 22.31 & 1.55 & 0.02 & 70.85 & $4.91^{*}$ & 0.05 \\
\hline Burnout & 76.37 & 1.87 & 0.04 & 45.29 & 1.11 & 0.01 & 0.07 & 0.002 & 0.000 & 666.94 & $16.36^{* * *}$ & 0.16 \\
\hline
\end{tabular}

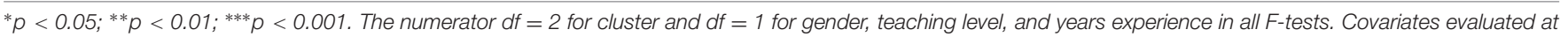
gender $=1.15$ and teaching level $=1.56$ in pre-service sample at gender $=1.86$, teaching level $=1.51$ and years teaching experience $=10.15$ for practicing sample.

\section{Cluster Profiles on Outcomes}

For pre-service teachers three outcomes differed by cluster (Table 4). First, significant differences emerged for preservice teachers' engagement. Specifically, low responsibility pre-service teachers were significantly less engaged than high responsibility pre-service teachers (Table 5). The effect approached significance when comparing the low responsibility and teacher-focused responsibility clusters as well. A similar pattern appeared for mastery approaches to instruction whereby pre-service teachers in the low responsibility cluster reported significantly lower classroom mastery goal structures than pre-service teachers in either the high responsibility or teacher-focused responsibility clusters. Finally, the reverse pattern emerged for classroom performance structures. In this case pre-service teachers in the low responsibility cluster reported higher intentions establish classroom performance structures than pre-service teachers in the other two clusters. High responsibility did not differ from teacher-focused responsibility on any outcome. Likewise, none of the clusters differed on sense of teaching efficacy or satisfaction with life.

For practicing teachers, contrary to our assumptions, no significant main effects emerged for cluster on any outcome variable (Table 4). Level of teaching had a significant effect on sense of teaching efficacy such that high school teachers reported higher feelings of efficacy $(M=82.98$, $S D=7.79)$ than elementary school teachers $(M=78.34$, $S D=10.10)$. Level of teaching also had a statistically significant effect on classroom mastery structures such that high school teachers reported lower endorsement of mastery structures $(M=14.63, S D=2.81)$ than elementary school teachers $(M=15.64, S D=2.72)$. As suggested by the correlations, there was also a significant relationship between years teaching experience and each outcome such that years of experience was associated with more efficacy, engagement, mastery goal structures, and fewer performance goal structures. Teachers with more experience also reported higher levels of burnout.

\section{DISCUSSION}

The purpose of this research was to examine how pre-service and practicing teachers combine their personal responsibilities and evaluate if particular combinations are more advantageous for specific outcomes. Different stories emerged for pre-service compared to practicing teachers both in terms of how personal responsibilities were combined and how personal responsibility related to outcomes. We focus on how the results are similar or different for pre-service and practicing teachers and what this implies for the developmental trajectory of teachers. First we discuss why a teacher-focused responsibility cluster emerged for pre-service teachers whereas a student-outcome focused responsibility cluster emerged for practicing teachers. Second, we examine the impact of different clusters on outcomes. Third, we explore the relative levels of endorsement in each domain of responsibility. Finally, we examine the limitations of this research and propose directions for future research.

\section{Differences in Clusters between Pre-service and Practicing Teachers}

The cluster solutions differed for pre-service and practicing teachers. A group of pre-service teachers emerged who reported higher levels of responsibility for their own teaching and their relationships with students than for students' motivation and achievement. From the perspective of Attribution Theory (Weiner, 1985), this cluster may be distinguishing responsibilities for which they can exert personal control, namely how well they teach and what kinds of relationships they establish with students, from responsibilities that they are less able to control, namely how motivated students are and their levels of achievement. In contrast, for practicing teachers an opposite group emerged that emphasized student motivation and achievement over responsibilities for teaching and relationships. One explanation for this difference may be the context in which pre-service versus practicing teachers exist: On a daily basis pre-service teachers are students, learning to teach, and presumably looking forward toward their career. 


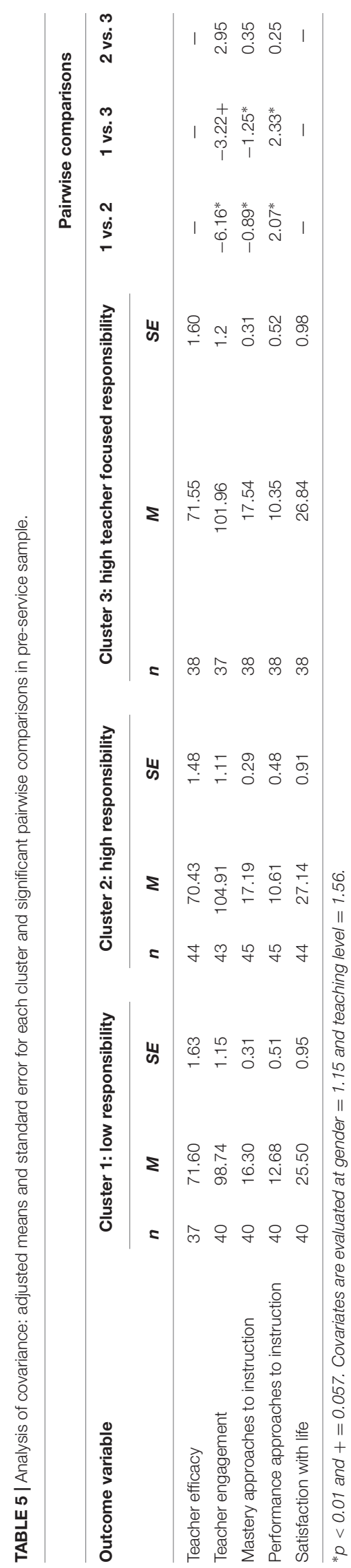

In contrast, on a daily basis practicing teachers face the demands of students, parents, and other stakeholders with the opportunity to focus on past events. These contexts may influence the responsibilities that are most salient for each group. Pre-service teachers may focus on why they chose to pursue teaching, many of whom did so to help children (Beck and Kosnik, 2002) perhaps heightening their sense of personal responsibility to maintain relationships (Lauermann and Karabenick, 2011a). Similarly, as students, pre-service teachers are learning to be "good" teachers making the responsibility for their own teaching one that they consider regularly. In contrast, practicing teachers may experience more frequent reminders that they are responsible for student achievement and as they face classroom management challenges (Evertson and Weinstein, 2006) they may understand how important student motivation is in sustaining relationships and supporting achievement. Of course our samples of preservice and practicing teachers are separate cohorts and do not represent a longitudinal sample. As such, although we can record these differences, they do not represent a truly developmental trajectory.

\section{Impact of Cluster Membership on Outcomes}

For pre-service teachers, although membership in either the high responsibility cluster or the teacher-focused responsibility cluster implied different priorities from a responsibility perspective, they appear to have the same consequences in terms of pre-service teachers' outcomes. Either high responsibility in all domains or feeling dominantly responsible for ones own teaching and relationships resulted in greater levels of engagement, more support of classroom mastery goal structures, and less support of classroom performance goal structures than being in the low responsibility cluster. In other words, our evidence suggests that more responsibility is more beneficial for pre-service teachers than less responsibility. Two possible explanations come to mind. First, from the perspective of teacher identity, pre-service teachers who have internalized more domains of personal responsibility may be showing a more fully developed professional identity than those who report lower levels of these responsibilities (Sutherland et al., 2010). It has been argued that "what may result from a teacher's realization of his or her identity, in performance within teaching contexts, is a sense of agency, of empowerment to move ideas forward, to reach goals or even to transform the context" (Beauchamp and Thomas, 2009, p. 183). This association between identity and agency can explain why pre-service teachers in the high or high-control responsibility clusters felt more engaged and mastery focused and less performance focused than those in the low cluster. Second, it is possible that pre-service teachers are unrealistically optimistic about their abilities to meet these responsibilities (Weinstein, 1989; Biddle, 1997). In other words, because they are not yet in full-time teaching positions pre-service teachers do not bear the full weight of the personal responsibilities or have to deal with failing to meet them. Indeed Lauermann and Karabenick (2011b) postulated that a curvilinear relationship may emerge 
when assumed responsibilities cannot be met - a reality that these pre-service teachers have not yet had to face.

In contrast, for practicing teachers, there were no statistically significant differences between clusters on any outcome. Instead, it seems that for this sample years of teaching experience outdid any combination of responsibility. Teachers with more experience reported higher levels of efficacy, engagement, classroom mastery goal structures along with lower levels of classroom performance goal structures and more burnout. On the one hand this paints a picture of experienced teachers who feel competent in their professional roles and choose adaptive instructional practices for their students and yet still suffer from symptoms of burnout. On the other hand, this suggests that novice teachers are less confident and appear less inclined to use adaptive instructional practices (Pillen et al., 2013; Daniels, 2015). If they are able to persist, experience in and of itself can help alleviate these negative feelings for novice teachers, but the ability to persist is more tenuous and our results do not help us better understand how to support novice teachers from the perspective of balancing their personal responsibilities.

\section{Mean Level Endorsement of Personal Responsibilities}

Despite the emergence of different combinations of responsibilities, the rank order endorsement of each responsibility was the same for pre-service and practicing teachers: Both samples most strongly reported feeling personally responsible for their own teaching, followed by relationships, then achievement, and finally for student motivation. This order of endorsement has been recorded in previous research (Berger et al., 2013; Lauermann, 2013; Daniels et al., 2016) and raises concerns about why teachers report such low levels of responsibility for student motivation particularly in an educational climate where intrinsic motivation is often in short supply (Legault et al., 2006; Usher and Kober, 2012). One possible explanation is that pre-service and practicing teachers may view motivation as an innate quality that cannot be influenced (Dweck, 2006). This is an empirical question that could be answered through future research and would provide valuable insight into understanding why certain responsibilities appear to be routinely endorsed less than others.

It is also interesting to note that pre-service teachers had a wider range of scores with nearly 2.5 points on the seven point scale separating their highest and lowest domains of personal responsibility. In contrast, practicing teachers had a much narrower range with about 1.5 points separating their lowest and high domains. Extant research shows that pre-service teachers may overestimate their capacities in comparison to practicing teachers (e.g., Pendergast et al., 2011) in part because they do not fully understand the realities of the classroom (Lortie, 1975). Longitudinal research would be helpful to figure out if pre-service teachers temper their endorsement of responsibilities when they begin teaching as they have done for other beliefs (e.g., Daniels, 2015).

\section{Limitations and Directions for Future Research}

The results of this research need to be interpreted in light of the following four limitations. First, both studies relied exclusively on self-report data. Although this is an efficient way to bring data to bear on the current research questions, future research may want to augment this perspective with observations of teaching practices, student evaluations of teacher engagement, and administrator perspectives. Second, we chose our clusters for theoretical and not statistical reasons. Thus, these clusters need to be replicated in independent samples and using more contemporary approaches to examining profiles such as latent class analysis which was precluded by our limited sample size. Third, the research presented herein represented a snapshot of responsibility in separate samples of pre-service and practicing teachers and not longitudinal data. Future research could benefit from longitudinal designs that advance our understanding of when pre-service teachers begin to adopt these responsibilities, if they shift in terms of how they are combined and when that occurs, and whether or not mean level endorsement changes over time. This would also allow investigations into possible curvilinear effects of responsibility as suggested by Lauermann and Karabenick (2011b). Fourth, although we selected outcomes that are often associated with effective teaching (e.g., Hattie, 2009) they do not allow us to infer how teachers' personal responsibilities impact students' actual outcomes. Future research would be wise to collect student achievement data and connect this to teachers' personal responsibilities.

\section{CONCLUSION}

The implications of the current results suggest that teacher education programs should help pre-service teachers to assume personal responsibilities associated with the profession because during their training more responsibility is associated with more effective cognitions. Once practicing, it seems that time will contribute more meaningfully to their professional and personal outcomes than focusing on specific responsibilities either in isolation or in combination. Both of these perspectives provide ample room for future research and particularly highlight the importance of examining personal responsibility in both preservice and practicing teachers because important differences may exist in terms of how personal responsibility is developed.

\section{ETHICS STATEMENT}

This study was carried out in accordance with the recommendations of Research Ethics and Management Online (REMO) System at the University of Alberta. The specific protocol approval numbers are: Pro00054513 and Pro00035849. An Information Letter explaining participants' rights was presented at the beginning of the questionnaire and then informed consent was given when participants began the questionnaire. 


\section{AUTHOR CONTRIBUTIONS}

LD was the lead author in conceptualizing the research and writing the manuscript. AR and LG contributed to all steps of the research and then critically reviewed and revised the manuscript. All authors accept accountability for the final version of the manuscript.

\section{REFERENCES}

Alberta Teachers' Association (1999). Alberta Teachers: A Workload Study [Research Monograph 37]. Edmonton, AB: The Alberta Teachers' Association.

Alberta Teaches' Association (2013). Teaching in the Early Years of Practice: A Five-Year Longitudinal Study. Available at: https://www.teachers.ab.ca/ SiteCollectionDocuments/ATA/Publications/Research/Teaching\%20in\% 20the\%20Early\%20Years\%20of\%20Practice\%20(PD-86-19b).pdf

Australian Primary Principals' Association (2006). Reports on the Experiences of Beginning Teachers Canberra. Canberra, ACT: Australian Primary Principals' Association.

Bandura, A. (2006). Toward a psychology of human agency. Perspect. Psychol. Sci. 1, 164-180. doi: 10.1111/j.1745-6916.2006.00011.x

Beauchamp, C., and Thomas, L. (2009). Understanding teacher identity: an overview of issues in the literature and implications for teacher education. Camb. J. Educ. 39, 175-189. doi: 10.1080/03057640902902252

Beck, C., and Kosnik, C. (2002). Components of a good practicum placement: student teacher perceptions. Teacher Educ. Q. 29, 81-98.

Berger, J.-L., Girardet, C., and Aprea, C. (2013). Motivation, sense of responsibility, and classroom management self-reported practices in vocational teachers. Paper presented at the 15th biennial meeting of the European Association for Research in Learning and Instruction, Munich.

Biddle, B. J. (1997). "Recent research on the role of the teacher," in International Handbook of Teachers and Teaching, eds B. J. Biddle, T. L. Good, and I. F. Goodson (Amsterdam: Springer), 499-520. doi: 10.1007/978-94-0114942-6_14

Bishay, A. (1996). Teacher motivation and job satisfaction: a study employing the experience sampling method. Journal of Undergraduate Sciences 3, 147-155.

Broadfoot, P., Osborn, M., Gilly, M., and Paillet, A. (1988). What professional responsibility means to teachers: national contexts and classroom constants. $\mathrm{Br}$. J. Sociol. Educ. 9, 265-287. doi: 10.1080/0142569880090302

Daniels, L. M. (2015). From pre-service to practicing teacher: considering the stability of personal and classroom mastery and performance goals. Educ Psychol. 35, 984-1005. doi: 10.1080/01443410.2013.870329

Daniels, L. M., Radil, A. I., and Wagner, A. (2016). Concordance between preservice teachers' personal responsibilities and intended instructional practices. J. Exp. Educ. 84, 529-553. doi: 10.1080/00220973.2015.1054333

Deci, E. L., Spiegel, N. H., Ryan, R. M., Koestner, R., and Kauffman, M. (1982). Effects of performance standards on teaching styles: Behavior of controlling teachers. J. Educ. Psychol. 74:852. doi: 10.1037/0022-0663.74.6.852

Diener, E., Emmons, R. A., Larsen, R. J., and Griffin, S. (1985). The satisfaction with life scale. J. Pers. Assess. 49, 71-75. doi: 10.1207/s15327752jpa4901_13

Durksen, T. (2015). Promoting Professional Growth: A Developmental and Motivational Approach to Teachers' Professional Learning. Ph.D. dissertation, University of Alberta, Edmonton, AB.

Dweck, C. S. (2006). Mindset: The New Psychology of Success. New York, NY: Random House.

Evertson, C. M., and Weinstein, C. S. (2006). A Handbook of Classroom Management: Research, Practice, and Contemporary Issues. Mahwah, NJ: Lawrence Erlbaum Associates.

Fischman, W., DiBara, J. A., and Gardner, H. (2006). Creating good education against the odds. Camb. J. Educ. 36, 383-398. doi: 10.1080/03057640600866007

Flink, C., Boggiano, A. K., and Barrett, M. (1990). Controlling teaching strategies: undermining children's self-determination and performance. J. Pers. Soc. Psychol. 59, 916-924. doi: 10.1037/0022-3514.59.5.916

Foster, D. (2017). Teacher Recruitment and Retention in England. Hours of Commons Library Briefing Paper: No 7222. Available at: http://researchbriefings.parliament.uk/ResearchBriefing/Summary/CBP-7222

\section{ACKNOWLEDGMENTS}

This work was supported by a Social Sciences and Humanities Research Council of Canada (SSHRC) Insight Grant (435-2015-0216) awarded to the first author and doctoral scholarships from SSHRC to the second and third authors.

Guskey, T. R. (1981). Measurement of responsibility teachers assume for academic successes and failures in the classroom. J. Teach. Educ. 32, 44-51. doi: 10.1177/ 002248718103200310

Hattie, J. (2009). Visible Learning: A Synthesis of Over 800 Meta-Analyses Relating to Achievement. New York, NY: Routledge.

Huberty, C. J., Jordan, E. M., and Brandt, W. C. (2005). "Cluster analysis in higher education research," in Higher Education: Handbook of Theory and Research, ed. J. C. Smart (Amsterdam: Springer), 437-457. doi: 10.1007/1-4020-3279-X_8

Klassen, R. M., Bong, M., Usher, E. L., Chong, W. H., Huan, V. S., Wong, I. Y., et al. (2009). Exploring the validity of a teachers' self-efficacy scale in five countries. Contemp. Educ. Psychol. 34, 67-76. doi: 10.1016/j.cedpsych.2008.08.001

Klassen, R. M., and Chiu, M. M. (2011). The occupational commitment and intention to quit of practicing and pre-service teachers: influence of selfefficacy, job stress, and teaching context. Contemp. Educ. Psychol. 36, 114-129. doi: 10.1016/j.cedpsych.2011.01.002

Klassen, R. M., and Durksen, T. L. (2014). Weekly self-efficacy and work stress during the teaching practicum: a mixed methods study. Learn. Instruct. 33, 158-169. doi: 10.1016/j.learninstruc.2014.05.003

Klassen, R. M., and Tze, V. M. C. (2014). Teachers' self-efficacy, personality, and teaching effectiveness: a meta-analysis. Educ. Res. Rev. 12, 59-76. doi: 10.1016/ j.edurev.2014.06.001

Klassen, R. M., Yerdelen, S., and Durksen, T. L. (2013). Measuring teacher engagement: development of the engaged teachers scale (ETS). Frontline Learn. Res. 1:33-52. doi: 10.14786/flr.v1i2.44

Kyriacou, C. (2001). Teacher stress: directions for future research. Educ. Rev. 53, 27-35. doi: 10.1080/00131910120033628

Lauermann, F. (2014). Teacher responsibility from the teachers' perspective. Int. J. Educ. Res. 65, 75-89. doi: 10.1016/j.ijer.2013.09.005

Lauermann, F., and Karabenick, S. (2011a). Motivation to become a teacher, teacher responsibility, and implications for mastery and performance approaches to instruction. Paper presented at the annual meeting of the American Educational Research Association, New Orleans, LA.

Lauermann, F., and Karabenick, S. A. (2011b). Taking teacher responsibility into account(ability): explicating its multiple components and theoretical status. Educ. Psychol. 46, 122-140. doi: 10.1080/00461520.2011.558818

Lauermann, F., and Karabenick, S. A. (2013). The meaning and measure of teachers' sense of responsibility for educational outcomes. Teach. Teacher Educ. 30, 13-26. doi: 10.1016/j.tate.2012.10.001

Lauermann, F. V. (2013). Teacher Responsibility: Its Meaning, Measure, and Educational Implications. Ph.D. dissertation, Hebrew University of Jerusalem, Jerusalem.

Legault, L., Green-Demers, I., and Pelletier, L. (2006). Why do high school students lack motivation in the classroom? Toward an understanding of academic amotivation and the role of social support. J. Educ. Psychol. 98, 567-582. doi: 10.1037/0022-0663.98.3.567

Lortie, D. (1975). Schoolteacher: A Sociological Study. Chicago, IL: University of Chicago Press.

Manthei, R., Gilmore, A., Tuck, B., and Adair, V. (1996). Teacher stress in intermediate schools. Educ. Res. 38, 3-19. doi: 10.1080/00131889603 80101

Martin, R. R., Dolmage, R., and Sharpe, D. (2012). Seeking Wellness: Descriptive Findings from the Survey of the Work Life and Health of Teachers in Regina and Saskatoon. Saskatoon, SK: Saskatchewan Teachers' Federation.

Maslach, C., Jackson, S. E., and Leiter, M. P. (1996). Maslach Burnout Inventory Manual. Palo Alto, CA: Consulting Psychologists Press.

McManus, I. C., Winder, B. C., and Gordon, D. (2002). The causal links between stress and burnout in a longitudinal study of UK doctors. Lancet 359, 2089-2090. doi: 10.1016/S0140-6736(02)08915-8 
Midgley, C., Maehr, M., Hruda, L., Anderman, E., Amerman, L., Freema, K., et al. (2000). Manual for the Patterns of Adaptive Learning Scales. Ann Arbor, MI: University of Michigan.

Montgomery, C., and Rupp, A. A. (2005). A meta-analysis for exploring the diverse causes and effects of stress in teachers. Can. J. Educ. 28, 458-486. doi: 10.2307/ 4126479

National Commission on Teaching and America's Future (2007). Policy Brief: The High Cost of Teacher Turnover. Washington, DC: Author.

Pelletier, L., Seguin-Levesque, C., and Legault, L. (2002). Pressure from above and pressure from below as determinants of teachers' motivation and teaching behaviors. J. Educ Psychol. 94, 186-196. doi: 10.1037//0022-0663. 94.1.186

Pendergast, D., Garvis, S., and Keogh, J. (2011). Pre-Service student-teacher selfefficacy beliefs: an insight into the making of teachers. Austr. J. Teacher Educ. 36, 46-57. doi: 10.14221/ajte.2011v36n12.6

Pillen, M., Beijaard, D., and Brok, P. D. (2013). Tensions in beginning teachers' professional identity development, accompanying feelings and coping strategies. Eur. J. Teacher Educ. 36, 240-260. doi: 10.1080/02619768.2012. 696192

Ryan, R. M., and Weinstein, N. (2009). Undermining quality teaching and learning: a self-determination theory perspective on high-stakes testing. Theory Res. Educ. 7, 224-233. doi: 10.1177/1477878509104327

Sutherland, L., Howard, S., and Markauskaite, L. (2010). Professional identity creation: examining the development of beginning preservice teachers' understanding of their work as teachers. Teach. Teacher Educ. 26, 455-465. doi: 10.1016/j.tate.2009.06.006

Tschannen-Moran, M., and Woolfolk Hoy, A. (2001). Teacher efficacy: capturing an elusive construct. Teach. Teacher Educ. 17, 783-805. doi: 10.1016/S0742051X(01)00036- 1

Usher, A., and Kober, M. (2012). Student Motivation: An overlooked Piece of School Reform. Available at: http://www.cep-dc.org/displayDocument.cfm? DocumentID $=405$
Weiner, B. (1985). An attributional theory of achievement motivation and emotion. Psychol. Rev. 92, 548-573. doi: 10.1037/0033-295X.92. 4.548

Weinstein, C. S. (1989). Teacher education students' preconceptions of teaching. J. Teacher Educ. 40, 53-60. doi: 10.1177/0022487189040 00210

Winter, D. G. (1992). "Responsibility," in Motivation and Personality: Handbook of Thematic Content Analysis, eds C. P. Smith, J. W. Atkinson, D. C. McClelland, and J. Veroff (New York, NY: Cambridge University Press), 500-505. doi: 10.1017/CBO9780511527937.036

Wormington, S. V., and Linnenbrink-Garcia, L. (2016). A new look at multiple goal pursuit: the promise of a person-centered approach. Educ. Psychol. Rev. 1-39. doi: 10.1007/s10648-016-9358-2

Zee, M., and Koomen, H. M. Y. (2016). Teacher self-efficacy and its effects on classroom processes, student academic adjustment, and teacher well-being: a synthesis of 40 years of research. Rev. Educ. Res. 86, 981-1015. doi: 10.3102/ 0034654315626801

Conflict of Interest Statement: The authors declare that the research was conducted in the absence of any commercial or financial relationships that could be construed as a potential conflict of interest.

The reviewer LIFF and handling Editor declared their shared affiliation, and the handling Editor states that the process nevertheless met the standards of a fair and objective review.

Copyright (c) 2017 Daniels, Radil and Goegan. This is an open-access article distributed under the terms of the Creative Commons Attribution License (CC BY). The use, distribution or reproduction in other forums is permitted, provided the original author(s) or licensor are credited and that the original publication in this journal is cited, in accordance with accepted academic practice. No use, distribution or reproduction is permitted which does not comply with these terms. 